\title{
O PAPEL DA CATEGORIA CONHECIMENTO NOS PROCESSOS DE COMPREENSÃO LEITORA
}

Alessandra BALDO

UFPel

Resumo: Perfetti et al (1996) dividem em duas grandes categorias os componentes presentes na compreensão leitora: a de processos e a de conhecimento. Na primeira estão os processos lexicais, a capacidade da memória de trabalho, a realização de inferências e o monitoramento da compreensão; na segunda, o significado das palavras e o conhecimento de domínio. O objetivo do presente artigo é mostrar a importância dos tipos de conhecimento implicados na segunda categoria para o processo global de compreensão leitora. Para tanto, as estratégias de leitura utilizadas por leitores adultos com escores mais altos de compreensão leitora serão comparadas com as utilizadas por leitores com escores mais baixos, ao responderem a questões específicas de inferência de vocabulário.

Palavras-chave: compreensão leitora; conhecimento de palavras; conhecimento de domínio; estratégias de leitura.

Resumen: Perfetti et al (1996) dividen en dos grandes categorías los componentes presentes en la comprensión lectora: la de los procesos y la del conocimiento. En la primera están los procesos léxicos, la capacidad de la memoria de trabajo, la realización de inferencias y el monitoreo de la comprensión; la segunda, el significado de las palabras y el conocimiento de dominio. El objeto de este artículo es mostrar la importancia de los tipos de conocimientos envueltos en la segunda categoría hacia el proceso global de comprensión lectora. Para ello, las estrategias de lectura utilizadas por los lectores adultos con niveles más elevados de comprensión lectora serán comparadas con las utilizadas por lectores con niveles más inferiores, basadas en las contestaciones a las preguntas específicas de inferencias de vocablos.

Palabras clave: comprensión lectora; conocimiento de palabras; conocimiento de dominio; estrategias de lectura. 
Abstract: Perfetti et al (1996) classify into two main categories the reading comprehension components: the process and the knowledge categories. While lexical processes, working memory capacity, inference making and comprehension monitoring are situated in the first one, word knowledge and domain knowledge are placed in the second one. This paper aims at showing the relevance of the types of knowledge that make up the second category to the overall reading comprehension process. In order to do so, the strategies used by adult readers with high reading scores were compared with the strategies used by adult readers with low reading scores, while answering to vocabulary-related items of a reading test.

Key-words: reading comprehension; word knowledge; domain knowledge; reading strategies.

\section{Introdução}

Com base em nossa experiência como leitores, sabemos que, sem o conhecimento do significado das palavras presentes no texto, o processo de compreensão sequer inicia. Ainda que outros fatores estejam implicados na compreensão leitora, o conhecimento de vocabulário tem um caráter único na medida em que ele é o responsável pelo desencadeamento de outros processos específicos de compreensão como, por exemplo, a realização de inferências e o monitoramento da compreensão.

Demonstrando a procedência dessa afirmação, uma análise de achados de pesquisa realizada por Anderson e Freebody (1981) mostrou que o conhecimento das palavras aparece como um preditor mais refinado de compreensão do que a habilidade de realizar inferências e de identificar as idéias principais de um texto. Além disso, vários autores têm mostrado, especialmente com relação à leitura na língua estrangeira, que um aperfeiçoamento na compreensão leitora pode ser atribuído a um aumento no conhecimento de vocabulário (BECK; PERFETTI; MCKEOWN, 1982; STAHL，1983; GRABE; STOLLER; 1997).

O conhecimento das palavras, no entanto, não é o único tipo de conhecimento necessário durante a leitura. Também com base nesta experiência como leitores, sabemos que, ao ativarmos o significado de determinadas palavras, ativamos também um 
conhecimento mais geral, comumente denominado na literatura de enciclopédico ou prévio. Porque a leitura não ocorreu em um vácuo sendo ela um evento de linguagem, e o texto, assim, pertencendo a um determinado gênero textual -, a importância desse tipo de conhecimento para o processo de compreensão leitora torna-se evidente.

Como esses dois tipos de conhecimento, pelo que vimos acima, são indissociáveis, neste artigo procuramos ilustrar essa interrelação com base na teoria de Perfetti et al (1996), a partir de estratégias utilizadas durante a resposta a itens de inferência vocabular presentes em um teste de compreensão leitora. Como poderá ser verificado na seção seguinte, uma das razões da escolha desta teoria como suporte para a análise dos dados foi o fato de prever a integração entre o conhecimento de palavras e o conhecimento prévio. ${ }^{1}$

\section{$1 \mathrm{O}$ conhecimento como componente da compreensão leitora}

Tudo o que pode ser identificado como um componente do processo de compreensão leitora também pode ser identificado como causador de falha nesse processo. Essa foi a conclusão à qual Perfetti et al (1996) chegaram com base no baixo desempenho em leitura de três dos quatro universitários que forneceram os dados para a realização de seu estudo. Assim, além dos já reconhecidos (i) processos lexicais e da (ii) capacidade limitada da memória de trabalho, os autores identificaram outras causas de dificuldades de compreensão leitora. ${ }^{2}$ A lista expandida dos autores prevê também a (iii) realização de inferências e (iv) o monitoramento da compreensão, componentes agrupados juntamente com os dois anteriores na categoria de processos, e ainda (v) o significado das palavras e o (vi) conhecimento de domínio, estes dois últimos classificados na categoria de conhecimento.

Mesmo pertencendo a categorias distintas, cada um desses componentes se inter-relaciona. Um dos exemplos que os autores

\footnotetext{
${ }^{1}$ Em Perfetti et al (1996), esse último tipo de conhecimento é denominado de conhecimento de domínio (conforme seção 1).

2 Perfetti (1985), na teoria que cunhou de "Teoria da Eficiência Verbal", havia identificado os processos lexicais e a capacidade limitada da memória de trabalho como as duas fontes principais de falha na compreensão leitora.
} 
utilizam para mostrar esse inter-relacionamento é a estratégia de monitoramento da compreensão: enquanto o automonitoramento está diretamente relacionado à representação que o leitor faz do texto, essa representação, por sua vez, é dependente da adequação das inferências construídas por ele à medida que processa a informação presente no texto.

Com relação à categoria conhecimento, os autores apontam que, muitas vezes, ao tratar do tema, a literatura deixa perpassar certo desconforto, no sentido de que seria bem mais simples investigar os processos de compreensão leitora sem ela. Perfetti et al (1996) reconhecem que talvez o papel desempenhado pelo conhecimento no "desencadeamento de processos importantes para a compreensão" tenha sido negligenciado, especialmente "o conhecimento necessário para controlar coisas como o monitoramento da compreensão e para a geração de inferências" (p. 147).

A opção por separar o conhecimento de palavras em uma categoria distinta da atribuída aos processos lexicais pode ser entendida como um esforço para acabar com essa possível negligência, considerando-se que a justificativa para fazê-lo está calcada em dois princípios dificilmente discutíveis: (i) problemas em entender as palavras no texto causarão problemas no entendimento do texto; (ii) embora os leitores possam inferir o significado das palavras, há um limite para a utilidade dessa estratégia.

No que diz respeito ao conhecimento de domínio, Perfetti et al (1996), ao fornecerem uma definição para o termo - "conceitos que são parte do background de qualquer texto" (p. 142) - esclarecem que este tem um papel crítico na construção de uma representação adequada do texto, na medida em que possibilita a relação entre a representação lingüística que o leitor faz do texto e a representação da situação baseada em inferências mais complexas. Por fim, os autores enfatizam que tanto o conhecimento de palavras como o conhecimento de domínio estão intimamente relacionados, já que os conceitos em um domínio específico são expressos através de um vocabulário específico.

$\mathrm{Na}$ seção seguinte, a importância do conhecimento será avaliada a partir da análise das estratégias empregadas nas questões de 
inferência de vocabulário pelos quatro sujeitos com escores mais altos de compreensão leitora, por um lado, e, por outro, pelos quatro sujeitos com escores mais baixos nessas mesmas questões, em um estudo que contou com 20 participantes (BALDO, 2006). ${ }^{3}$

\section{Metodologia}

A pesquisa da qual provêm os dados para esse artigo teve como sujeitos 20 alunos do Programa de Pós-Graduação em Letras de uma instituição de ensino superior do Rio Grande do Sul. Alguns dos sujeitos tinham na língua estrangeira sua área de formação/ especialização, o que pode ser interpretado como uma possível explicação para os escores mais baixos em compreensão leitora em língua materna.

Foi selecionado um texto da revista Veja, intitulado "1.200.000 espectadores" (edição de outubro de 2002), com base no qual foi elaborada uma atividade de compreensão leitora - um questionário com doze questões - a fim de verificar o nível de compreensão do material lido. $\mathrm{O}$ texto possui três partes principais: a primeira focaliza o sucesso de bilheteria, com uma tentativa de explicação para isso; a segunda remete às críticas recebidas pelo filme; a terceira traz um histórico e os planos profissionais do diretor, Fernando Meirelles.

Das doze questões da atividade de compreensão leitora, quatro delas foram reservadas para testar a inferência de vocabulário, conforme se pode visualizar no Quadro I a seguir.

\footnotetext{
${ }^{3}$ Trata-se de minha tese de Doutorado (ver referências), cujos dados e metodologia estão re-enfocados aqui para o tratamento das questões específicas tratadas neste artigo.
} 
Quadro I - Operações cognitivas previstas para cada questão

\begin{tabular}{|c|c|}
\hline Questões & Operações cognitivas \\
\hline Questão 01 & Síntese assunto principal \\
\hline Questão 02 & Inferência \\
\hline Questão 03 & Inferência \\
\hline Questão 04 & $\begin{array}{c}\text { Identificação da informação explícita ou } \\
\text { em paráfrase }\end{array}$ \\
\hline Questão 05 & $\begin{array}{c}\text { Identificação da informação explícita ou } \\
\text { em paráfrase }\end{array}$ \\
\hline Questão 06 & $\begin{array}{c}\text { Identificação da informação explícita ou } \\
\text { em paráfrase }\end{array}$ \\
\hline Questão 07 & $\begin{array}{l}\text { Identificação da informação explícita ou } \\
\text { em paráfrase }\end{array}$ \\
\hline Questão 08 & $\begin{array}{l}\text { Identificação da informação explícita ou } \\
\text { em paráfrase }\end{array}$ \\
\hline Questão 9a & Inferência de vocabulário \\
\hline Questão 9b & Inferência de vocabulário \\
\hline Questão 9c & Inferência de vocabulário \\
\hline Questão 9d & Inferência de vocabulário \\
\hline
\end{tabular}

Os sujeitos liam silenciosamente o texto, e após forneciam respostas orais ao questionário, por meio da técnica dos protocolos verbais, para a qual haviam sido previamente testados. As respostas eram gravadas em áudio e transcritas. Com base na transcrição dos dados, a pesquisadora inferia as estratégias de leitura empregadas pelos sujeitos para resolver cada uma das questões proposta na atividade de compreensão leitora, como também avaliava a compatibilidade das respostas com os dados presentes no texto, conforme avaliação prévia de dois especialistas em língua portuguesa.

Foram descritos três níveis de adequação de respostas totalmente adequado (TA), parcialmente adequado (PA) e inadequado (I). Cada questão valia 2 pontos. Assim, se uma resposta fosse considerada totalmente adequada, o escore seria 2; se parcialmente adequada, 1; se inadequada, 0 . Como havia 12 questões, o escore máximo que cada participante poderia alcançar seria 24. Para nossos objetivos de pesquisa, foram invalidados os dados dos sujeitos que 
não alcançaram pelo menos 12 pontos, ou seja, 50\% das respostas corretas.

Uma lista com 23 estratégias de leitura foi utilizada para a decodificação dos dados presentes nos protocolos. Esse material foi elaborado a partir de Sarig (1987) e Anderson (1991), mas adaptado para contemplar as informações verificadas nos protocolos verbais.

\section{Descrição}

Dos 20 participantes, foram selecionadas, para fins de análise comparativa, as estratégias utilizadas pelos 4 sujeitos com escores mais elevados (Sujeitos 05, 10, 16 e 19, conforme Tabela 1) e as estratégias utilizadas pelos 4 sujeitos com escores mais baixos (Sujeitos 01, 06, 09, 17, conforme Tabela 2 ) de compreensão leitora. Como dissemos anteriormente, o escore máximo que cada sujeito poderia alcançar era 24 pontos, e o mínimo, 12.

\begin{tabular}{|l|l|}
\hline $\begin{array}{l}\text { Sujeitos escores } \\
\text { mais altos }\end{array}$ & Escores \\
\hline Sujeito 05 & 23 \\
\hline Sujeito 10 & 22 \\
\hline Sujeito 16 & 21 \\
\hline Sujeito 19 & 24 \\
\hline
\end{tabular}

Tabela 1 - Escores mais altos

\begin{tabular}{|l|l|}
\hline $\begin{array}{l}\text { Sujeitos escores } \\
\text { mais baixos }\end{array}$ & Escores \\
\hline Sujeito 01 & 15 \\
\hline Sujeito 06 & 15 \\
\hline Sujeito 09 & 15 \\
\hline Sujeito 17 & 14 \\
\hline
\end{tabular}

Tabela 2 - Escores mais baixos

As estratégias de leitura empregadas pelos oito participantes aqui observados encontram-se discriminadas nas Tabelas 3 e 4 seguintes. A primeira contém os dados dos sujeitos com desempenho mais satisfatório em compreensão leitora, e a segunda, os dados dos sujeitos com desempenho menos satisfatório. Como essas estratégias estão identificadas por um número, a fim de possibilitar a análise, elas serão legendadas no Quadro 2. 


\begin{tabular}{|c|c|c|c|c|}
\hline $\begin{array}{c}\text { Estratégia(s) } \\
\text { utilizada(s) } \Rightarrow\end{array}$ & Questão 9a & Questão 9b & Questão 9c & Questão 9d \\
\hline $\begin{array}{c}\text { Sujeitos escores } \\
\text { altos }\end{array}$ & Est.11 & Est.11 & Est.11,10 & Est.1 \\
\hline Sujeito 05 & Est.11 & Est.11 & Est.11,10 & Est.11 \\
\hline Sujeito 10 & Est.1,6 & Est.11 & Est.10 & Est.1, 6 \\
\hline Sujeito 16 & Est.15,11 & $\begin{array}{c}\text { Est. } \\
\text { Sujeito 19 }\end{array}$ & Est.1,6 & Est.1,11,6 \\
\hline
\end{tabular}

Tabela 3 - Estratégias de leitura utilizadas nas questões de inferência de vocabulário pelos sujeitos com escores mais altos

\begin{tabular}{|c|c|c|c|c|}
\hline $\begin{array}{c}\text { Estratégia(s) } \\
\text { utilizada(s) } \Rightarrow\end{array}$ & $\begin{array}{c}\text { Questão } \\
9 a\end{array}$ & $\begin{array}{c}\text { Questão } \\
9 b\end{array}$ & Questão 9c & Questão 9d \\
\hline $\begin{array}{c}\text { Sujeitos escores } \\
\text { baixos }\end{array}$ & & & & \\
\hline Sujeito 01 & $\begin{array}{c}\text { Est. } \\
11,14,20\end{array}$ & Est.11 & Est.11,10 & Est.11 \\
\hline Sujeito 06 & Est.11 & Est.11 & Est.11/15 & Est.11/15,20,11 \\
\hline Sujeito 09 & Est.11 & Est.11 & Est.11,10 & Est.1 \\
\hline Sujeito 17 & Est.11 & Est.11 & Est.11,10 & Est.11 \\
\hline
\end{tabular}

Tabela 4 - Estratégias de leitura utilizadas nas questões de inferência de vocabulário pelos sujeitos com escores mais baixos 
Estratégia 1: recuperação da informação presente na memória;

Estratégia 6: retorno ao texto para confirmar uma resposta previamente formulada;

Estratégia 10: recorrência ao conhecimento extratextual; ${ }^{4}$

Estratégia 11: releitura da frase/parágrafo no qual a palavra/expressão está inserida;

Estratégia 14: repetição de parte ou de toda a questão;

Estratégia 15: uso de entonação tipo canto para facilitar a compreensão;

Estratégia 20: comentários para mostrar a dificuldade de entender e/ou responder à questão.

A fim de ser possível uma melhor visualização da freqüência de uso de cada uma das estratégias em questão pelos dois grupos de leitores, esses dados estão dispostos na Tabela 5 que se segue.

\footnotetext{
${ }^{4}$ Embora seja difícil separar a estratégia 1, recuperação da informação presente na memória, da estratégia 10 , recorrência ao conhecimento extratextual, já que as duas tratam de recuperação de informação na memória, procuramos utilizar o seguinte critério: quando o leitor recuperava informações presentes explicitamente no texto, inferíamos que a estratégia empregada era a de $n^{\circ} 1$; quando ele recorria ao conhecimento extratextual para fazer inferências e associações a partir da base textual, inferíamos que a estratégia empregada era a de $\mathrm{n}^{\mathrm{o}} 10$. Reconhecemos, no entanto, que a linha divisória entre elas é muito tênue.
} 


\begin{tabular}{|c|c|c|}
\hline Freqüência de Uso $\Rightarrow$ & \multirow{2}{*}{$\begin{array}{l}\text { Leitores com } \\
\text { Escores } \\
\text { Mais Altos }\end{array}$} & \multirow{2}{*}{$\begin{array}{l}\text { Leitores com } \\
\text { Escores } \\
\text { Mais Baixos }\end{array}$} \\
\hline Estratégias $\Downarrow$ & & \\
\hline $\begin{array}{l}\text { 1: recuperação da } \\
\text { informação sobre o texto } \\
\text { presente na memória }\end{array}$ & 5 & 1 \\
\hline $\begin{array}{l}\text { 6: retorno ao texto para } \\
\text { confirmar uma resposta } \\
\text { previamente formulada }\end{array}$ & 5 & 0 \\
\hline $\begin{array}{l}\text { 10: recorrência ao } \\
\text { conhecimento } \\
\text { extratextual }\end{array}$ & 3 & 3 \\
\hline $\begin{array}{l}\text { 11: releitura da } \\
\text { frase/parágrafo no qual a } \\
\text { palavra/expressão está } \\
\text { inserida }\end{array}$ & 11 & 16 \\
\hline $\begin{array}{c}\text { 14: repetição de parte ou } \\
\text { de toda a questão }\end{array}$ & 0 & 1 \\
\hline $\begin{array}{l}\text { 15: uso de entonação tipo } \\
\text { canto para facilitar a } \\
\text { compreensão }\end{array}$ & 1 & 1 \\
\hline $\begin{array}{c}\text { 20: comentários para } \\
\text { mostrar a dificuldade de } \\
\text { entender e/ou responder } \\
\text { à questão }\end{array}$ & 0 & 2 \\
\hline
\end{tabular}

Tabela 5 - Freqüência de uso das estratégias de leitura nas questões de inferência de vocabulário pelos leitores com escores mais altos e pelos leitores com escores mais baixos. 


\section{Análise dos Dados}

Um primeiro olhar para os dados agrupados na Tabela 5 são de grande utilidade para auxiliar no encaminhamento do tópico levantado neste artigo, ou seja, a relevância da categoria conhecimento para o processo de compreensão leitora, de acordo com Perfetti et al (1996). Como havíamos colocado inicialmente, o objetivo aqui seria ilustrar a procedência da teoria dos autores com base em uma comparação das estratégias utilizadas por sujeitos com níveis mais altos e mais baixos de compreensão leitora.

Começando com uma subversão da ordem, as estratégias de n. ${ }^{\circ} 20$, comentários para mostrar a dificuldade de entender e/ou responder à questão número 15 , uso de entonação tipo canto para facilitar a compreensão e número 14 , repetição de parte ou de toda a questão, não parecem carecer de uma análise mais detalhada, dada a sua pouca utilização dessas pelos sujeitos. Se algo pode ser dito, é que seria esperado que o emprego da estratégia 20 (comentários para mostrar a dificuldade de entender e/ou responder à questão) aparecesse somente entre os sujeitos com escores mais baixos, o que se confirmou.

Com relação à estratégia 10 , recorrência ao conhecimento extratextual, houve exatamente o mesmo número de ocorrências entre os dois grupos de leitores. Vale notar ainda que o número de ocorrências é pouco expressivo, mesmo para um grupo de quatro leitores. Já para a estratégia mais empregada pelos dois grupos de leitores, a de $\mathrm{n}^{\circ} 11$, releitura da frase/parágrafo no qual a palavra/ expressão está inserida, pode-se perceber que houve um número maior de ocorrências entre os leitores com níveis mais baixos de compreensão leitora - 16 ocorrências, em comparação a 11 ocorrências no outro grupo. Como veremos a seguir, isso se explica pelo fato de que os leitores com escores mais altos na atividade de leitura conseguiram utilizar as estratégias 1, recuperação de informação sobre o texto presente na memória, e 6 , retorno ao texto para confirmar uma resposta previamente formulada, mais freqüentemente do que os com escores mais baixos, a substituindo então pela estratégia 11 , de releitura da frase/parágrafo em que a palavra/expressão se encontrava.

Esses dados constituem-se nos mais interessantes para nossos objetivos, em particular os advindos das freqüências de uso das estratégias 1, recuperação da informação sobre o texto presente na 
memória e 6, retorno ao texto para confirmar uma resposta previamente formulada. Em termos proporcionais, encontramos aqui a maior diferença entre os dois grupos de leitores: enquanto os sujeitos com escores mais altos utilizam 5 vezes a estratégia 1, os com escores mais baixo a utilizam somente 1 vez. Situação análoga é encontrada para a estratégia 6: os sujeitos com escores mais altos se valem dela 5 vezes para realizarem as inferências de vocabulário; os com escores mais baixos, nenhuma.

A utilização mais freqüente dessas estratégias pelos leitores com níveis mais altos de compreensão leitora poderia sugerir que eles já possuíam algum tipo de conhecimento sobre o vocábulo, especialmente com relação ao uso da estratégia 1 , recuperação da informação sobre o texto presente na memória. Naturalmente, ao resgatarem a informação sobre o texto, os sujeitos também resgatavam informações prévias, já que muitas das informações e conceitos apresentados no texto somente poderiam ter sido gravados pelos leitores devido ao que Perfetti et al (1996) denominaram de conhecimento de domínio. Se os leitores não possuíssem esse conhecimento de domínio, poder-se-ia argumentar, não haveria como iniciar o processo de inferência vocabular.

A utilização da estratégia 6 , retorno ao texto para confirmar uma resposta previamente formulada, pode ser vista, neste contexto, como uma etapa deste processo de inferência vocabular iniciado pela recuperação da informação presente na memória (estratégia 1). Assim, se observarmos, por exemplo, o comportamento cognitivo via estratégias de leitura dos sujeitos 16 (questões 9a e 9d) e 19 (questões 9b, 9c e 9d), demonstrado na Tabela 3, podemos notar que a inferência da palavra/expressão iniciou pela ativação na memória da informação sobre o texto lido, e finalizou com um retorno ao texto para confirmar a procedência dessa ativação.

Para ilustrar mais claramente esse processo, os protocolos verbais dos Sujeitos 16 e 19 ao formularem respostas a duas questões de inferência de vocabulário serão apresentados abaixo. No primeiro caso, temos a resposta do sujeito ao significado do advérbio "veladamente"; no segundo caso, ao significado da expressão "apartheid social brasileiro". As informações entre parênteses registram as observações que a entrevistadora fez durante a sessão de coleta de dados, bem como as interações verbais com os sujeitos. As reticências 
servem para mostrar uma pausa na fala do sujeito - devida, provavelmente, a uma reflexão sobre seu processo de compreensão.

\section{Sujeito 16 - Questão 9d}

Palavra: veladamente

Resposta: veladamente deve ser uma coisa que não é explícita, né, não sei se é isso, (volta ao texto e relê em silêncio a parte na qual a expressão se encontra) ele é veladamente acusado..., é, não é uma coisa explícita, é uma coisa velada, uma coisa implícita.

Estratégia(s) empregada(s): 1, recuperação da informação sobre o texto presente na memória; 6 , retorno ao texto para confirmar uma resposta previamente formulada.

Sujeito 19 - Questão 9c

Expressão: apartheid social brasileiro

Resposta: diferenças sociais do país, na linha 83 (volta rapidamente ao texto e relê em silêncio parte do segmento do texto em que a expressão está inserida), é, as diferenças sociais no Brasil.

(Entrevistadora: Já tinha visto essa expressão?)

Nessa expressão não lembro de ter visto, só apartheid.

Estratégia(s) empregada(s): 1, recuperação da informação sobre o texto presente na memória; 6 , retorno ao texto para confirmar uma resposta previamente formulada.

Uma análise desses dois excertos de protocolos nos possibilita perceber mais claramente a importância do conhecimento para o processo de compreensão leitora, mais especificamente aqui para a realização de inferências vocabulares. Embora o Sujeito 16 explicite que não tenha certeza sobre o significado da palavra - "deve ser uma coisa que não é explícita, né, não sei se é isso" -, ele mostra que possui uma idéia a respeito de um possível significado, construída, provavelmente, ao longo de sua vida de leitor. A partir desse conhecimento inicial é que ele volta ao texto para confirmar - ou não - sua idéia, o que, de acordo com sua hipótese, acontece de fato. Procedimento semelhante é verificado com base nas informações do Sujeito 19: ainda que a resposta direta ao significado da expressão leve 
a crer que ele já a conhecia previamente à leitura do texto - hipótese que é desconfirmada pelo próprio sujeito -, sabe-se que ele conhece o significado de apartheid. Assim, resgatando as informações do texto, o que necessariamente significava o resgate de informações de domínios específicos de conhecimento, ele consegue inferir o significado da expressão.

Por outro lado, mencionamos anteriormente que, caso os leitores não possuíssem o conhecimento de domínio adequado para recuperar as informações presentes no texto, poderia haver uma falha no processo de inferência vocabular, já que não haveria como utilizar a estratégia 1 , recuperação da informação presente na memória, para iniciar o processo de inferência. Comentamos, ainda, que os leitores com escores mais baixos, por não terem à disposição a estratégia 1 , necessitavam primeiramente reler a frase/parágrafo no qual a palavra/ expressão se encontrava, o que explicaria o uso mais freqüente da estratégia 1 (conforme Quadro 2). Para demonstrar isso, apresentamos a seguir os protocolos verbais dos Sujeitos 01 e 09, com os mesmos itens vocabulares ilustrados para os dois sujeitos do grupo com escores mais altos de compreensão, ou seja, o advérbio veladamente e a expressão apartheid social brasileiro. Para facilitar a compreensão, a parte que foi relida pelos sujeitos está italizada.

Sujeito 01 - Questão 9d

Palavra: veladamente

Protocolo verbal: Veladamente: vou ler (retorna ao texto e procura pela informação), sempre que um diretor vem do meio publicitário, caso de Salles, Meirelles e Andrucha, ele é veladamente acusado de usar seu arsenal.... Veladamente aqui é no sentido de que é certo de que ele vai ser acusado, certamente ele vai ser acusado disso. Pela frase, é isso.

Estratégia(s) empregada(s): 11, releitura da frase/parágrafo em que a palavra/expressão se encontra.

Sujeito 9 - Questão 9c

Expressão: apartheid social brasileiro

Protocolo verbal: apartheid social brasileiro. linha 85. Cidade de Deus aprofundou a discussão sobre o apartheid social brasileiro e virou matéria 
urgente. Ah, apartheid social brasileiro, comparando com o apartheid da África, imagino, querendo, né, mostrar, sei eu, ah, de novo, tirar alguma coisa de positivo de uma coisa tão violenta, que eram, por exemplo, as cenas na Cidade de Deus, ou o mundo em que vivem os protagonistas de Cidade de Deus. Apartheid social brasileiro, me parece uma coisa até meio irônico assim, Cidade de Deus aprofundou a discussão sobre o apartheid social brasileiro. Mas não é irônico, porque a mulher aqui, a escritora, só coloca o Fernando Meirelles pra cima. Eu acho que tá comparando com o apartheid africano e essa busca dos programas sociais brasileiros como uma coisa que tá na moda, que tá em voga.

(Entrevistadora: Já conhecias essa expressão antes?)

Sim, o apartheid.

(Entrevistadora: Mas a expressão toda, apartheid social brasileiro?)

Não, nunca tinha visto.

Estratégia(s) empregada(s): 11, releitura da frase/parágrafo em que a palavra/expressão se encontra; recorrência ao conhecimento extratextual.

Tanto o Sujeito 01 como o Sujeito 09 confirmam o uso mais freqüente da estratégia 11 por uma provável impossibilidade de construírem hipóteses sobre o significado das palavras/expressões a partir do resgate direto da memória das informações sobre o texto. ${ }^{5}$ No caso do Sujeito 01, essa falta de hipótese pode ter sido agravada por um contexto lingüístico pouco preciso. Aqui poderia entrar em cena a importância do conhecimento de domínio para a realização da inferência da palavra, já que, poder-se-ia pensar, se o leitor tivesse ativado

\footnotetext{
${ }^{5}$ Contudo, essa indisponibilidade não significa necessariamente que não se consiga chegar ao significado das palavras/expressões de um texto, via realização de inferências, a partir da estratégia da releitura, o que implicaria ir contra toda a evidência de pesquisa disponível até o momento. Se observarmos o comportamento dos Sujeitos 05 e 10, por exemplo, ilustrado na Tabela 3, observaremos que eles lançaram mão dessa estratégia, e esse movimento representou o início de uma tentativa bem-sucedida de inferência de significado. Nosso argumento aqui se refere a uma análise do comportamento desses leitores específicos.
} 
o conhecimento de que "eticamente, não é correto criticar colegas de profissão - pelo menos não abertamente", já que naquela parte do texto estava sendo feito um comentário sobre as críticas que diretores de cinema que têm formação como publicitários - e não como cineastas propriamente ditos - recebem de outros colegas, de formação "clássica". Como esse conhecimento faltou, ou não foi ativado, a inferência apropriada não pôde ocorrer.

Já no caso do Sujeito 09, houve a tentativa de construção de uma hipótese para o significado da expressão a partir do resgate de conhecimento extratextual - o apartheid na África. No entanto, a associação entre o conhecimento extratextual do sujeito e as informações presentes no texto não resultou em uma inferência apropriada. Embora o sujeito tenha mencionado em sua resposta a violência, a questão social, o apartheid na África, parece ter faltado um melhor monitoramento de todos esses dados com a base de texto, e a conseqüência foi uma compreensão inapropriada da expressão.

Desse modo, temos aqui um exemplo claro de como uma falha em construir uma inferência apropriada está relacionada a uma falha no processo de monitoramento da compreensão, e vice-versa, pois o principal "instrumento" que um leitor possui para rever o seu processo de monitoramento é o dar-se conta da procedência ou improcedência das inferências que constrói ao longo do processo de compreensão leitora.

\section{Considerações Finais}

No início deste artigo, destacamos que nosso objetivo seria mostrar a importância da categoria conhecimento, de acordo com a classificação de Perfetti et al (1996), para os processos de compreensão leitora. Para tanto, esclarecemos que faríamos uma comparação das estratégias utilizadas por leitores com escores mais altos e mais baixos de compreensão leitora, ao responderem especificamente a questões de inferência vocabular.

Com base na análise dos dados, verificamos que a maior diferença entre os dois grupos de leitores, em termos de utilização de estratégias, resumiu-se à utilização mais freqüente, pelos leitores com escores mais altos de compreensão, das estratégias que previam algum tipo de conhecimento prévio com relação aos vocábulos - ainda que 
isso não significasse o conhecimento do significado do vocábulo previamente à leitura do texto, como pôde ser verificado pela transcrição dos protocolos verbais. Assim, tomamos esse achado de pesquisa como um indicativo da procedência da teoria da Perfetti et al (1996), não somente com relação à relevância da categoria conhecimento para os processos de compreensão leitora, como também com relação à interdependência das duas categorias previstas pela teoria.

Antes de finalizar, é sempre importante notar que os dados deste estudo foram obtidos a partir dos protocolos verbais de 8 leitores, o que significa que, em termos estatísticos, não representam uma amostra significativa. Embora consideremos que nosso objetivo primeiro, ou seja, o de ilustrar a procedência da teoria de Perfetti et al com relação à relevância da categoria conhecimento para os processos de compreensão leitora, tenha sido cumprido, os dados aqui apresentados necessariamente devem ser interpretados dentro dos limites impostos pela pesquisa.

\section{Referências}

ANDERSON, N. J. Individual differences in strategy use in second language reading and testing. The Modern Language Journal, n. 75, p. 46072, 1991.

ANDERSON, R. C.; FREEBODY, P. Vocabulary and Knowledge . In: GUTRIE, J. T. Comprehension and teaching: research review. Newark, DE: International Reading Association, 1981.

BALDO, A. Estratégias de leitura na língua materna e na lingua estrangeira. 2006. Tese (Doutorado em Lingüística Aplicada) - Pontifícia Universidade Católica do Rio Grande do Sul, Porto Alegre.

BECK, I.L; PERFETTI, C.A; McKEOWN, M.G. Effects of text construction and instructional procedures for teaching word meanings on comprehension and recall. Journal of Educational Psychology, n. 74, 1982. 
GRABE, W.; STOLLER, F. Reading and vocabulary development in a second language. In: COADY, J; HUCKIN, T. Second Language Vocabulary Acquisition. Cambridge: Cambridge University Press, 1997.

PERFETTI, C. et al. Sources of Comprehension Failure: Theoretical Perspectives and Case Studies. In: CORNOLDI, C.; OAKHILL, J. (Eds). Reading Comprehension Difficulties. Mahwah, Nova Jérsei: Erbaum, 1996.

. Reading Ability. Nova Iorque: Oxford University Press, 1985.

1.200.000 ESPECTADORES. Revista Veja. São Paulo: Abril, ano 35, n. 39, 2002, p. 132-133.

SARIG, Gissi. High-Level reading in the first and in the foreign language: some comparative process data. In: DEVINE, J.; CARRELL, P.; ESKEY, D.E. (Eds.) Research in Reading in English as a Second Language. Washington. D.C.: TESOL, 1987.

STAHL, S. Differential word knowledge and reading comprehension. Journal of Reading Behaviour, n. 15, 1983. 